\title{
Concepts and Characteristics of Complex Systems and Final Energy Usage
} Maira Dzedzej, Hirdan Katarina de Medeiros Costa

\author{
Energy Program, Institute of Energy and Environment, University of Sao Paulo
}

\begin{abstract}
The growth, development and urban densification are related to consumption and energy dependence. In relation to the consumption of electric energy, such as cities and their regions with predominance of residential, commercial and more vulnerable services. It is vital the understanding of the various interactions between people and energy of utmost importance for 21 st century cities and their spatial behavior and distribution. Cities can be understood as Urban Energy Systems - SEU, which represent the combined processes of consumption and energy acquisition as a supply ofdemands of an urban population. Systems, represented by cities, regions, subdistricts and districts are like space units, infrastructure facilities consisting of homes, buildings, schools, business centers, large shopping centers and streets that connect these space units. The energy issue is closely related to a spatial occupation and distribution of cities. Therefore, this paper explores this conceptual discussion, based on the theoretical and philosophical development of socioecological systems, comes with the main objective of serving as a tool for subsidizing urban energy planning and a proposal of public policies for a reduction of urban energy vulnerability.
\end{abstract}

Keywords - urban energy systems, urban energy vulnerability, electricity, spatial analysis, public policies.

\section{INTRODUCTION}

Comprehending the several interactions between people and energy is the main point to understand $21^{\text {st }}$ century cities. In these cities, the so-called Urban Energy Systems (UES) are consolidated and represent the combined processes of consumption and acquisition of energy in order to meet the demands of an urban population, as defined by Jaccard (2006).

The UES include very diverse demands: heating and cooling of buildings, lighting services in both public and private areas, transportation and communication services, electric power for devices and others (RUTTER \& KEIRSTEAD, 2012).

In a society more and more dependent on, and connected to, electric services, the safety of the electricity distribution system is a determining factor for social wellbeing and maintenance of productive processes in cities and, due to its importance, it becomes a recurrent item in debates about public policies.

In order to contextualize societies' energy safety, some definitions are borrowed from other scientific areas, such as the concepts of vulnerability, resilience, and adaptability. There is an effort to uniform these different concepts; according to Gallopín (2006), this happens because they involve different areas of knowledge that are often unrelated as Evolutionary Biology, Ecology, Cultural Studies (interdisciplinary field of investigation Sociology, Anthropology, Philosophy, Literature), Computer Science and Engineering.

Thus, this article presents general and applied concepts in the context of energy safety of strongly urbanized areas from the point of view of urban energy systems. The conceptualization will consolidate the understanding and definition of urban energy vulnerability and, for example, could guide public policies in order to construct models for understanding energy systems in urban areas, which shall be greatly useful in planning and managing said systems.

In order to do this, general concepts such as vulnerability, resilience and adaptability will be explored, including contributions from several areas of knowledge on the theme. Clas sic concepts from the energy science will also be presented and they will support such discussions, such as: energy, electric energy, primary and secondary sources, and final uses. These concepts will be connected and applied to concepts such as socio-ecological systems, complex systems, urban energy systems, energy safety, global continuity performance (DGC), frequency and duration of failures (FEC, DEC), and others.

Then, these definitions will be extended into the context of urban energy system, resulting in the central point of this study: urban energy vulnerability and energy adaptability.

\section{CITIES AND SYSTEMS}

\subsection{Cities}

Many definitions presented for cities are based on historic, social, and political aspects. In this regard, some concepts by referenced authors are presented, pertinent to this research.

In Brazil, according to the Brazilian Institute of Geography and Statistics (IBGE, 2010), about $84.36 \%$ of 
the population lives in cities. In these urban spaces, the exchange of goods and services, culture and knowledge among habitants is outstanding via the energetic conditions fundamental to such habitants of urban life.

Cities are considered the great geographical expression of this century, that is, they are the consolidation of human society and economic, political, and social relations determine their growth. The urban space is shaped by the interdependencies among cities, which influences local environmental and energetic quality.

In this century, cities became, mainly, urban public spaces, scenery for major social, political and environmental issues, conflicts, inequality, and unbalance, where lies injustice and exclusion.

The low-income population who dwells in urban areas is directly affected by the fact that public authorities do not ensure their basic survival rights and by the deficiency in public policies that meet social and environmental demands.

This scenery is aggravated when one realizes the irrational use of natural resources, the inadequate infrastructure constructions and urban installations that impact the environment irreversibly and have their main effect as the deterioration of life quality in cities.

According to Lefebvre (2001), the urban space has a "conceived" character, that is, a homogenous space, abstractly, the place for social relations, for experience exchange; the space lived / perceived of representations and daily practices. At the same time, this abstract space works as an instrument, as control and as management for the State that it works as a controlling instrument for those owners of economic and political power.

Moreover, the author approaches the urban space as the result of a historical process of consolidation of cities that went through processes of industrialization and urbanization, a qualitative change, resulting of the way of life and daily practices of their population. The urban space must be considered the lived space and its place to understand urbanization.

When one analyses the meaning of the terms urban and urbanization under the critical perspective, one understands that their definitions go beyond the concept of cities and are defined from the condensation of social and spatial processes that allowed capitalism to go on and to reproduce its essential production relations and its own survival. Moreover, the urban space, for capitalism, is the conditioning and regulating agent of the socio-spatial contradictions.

In this line of thought, cities have different uses and can be articulated and fragmented at the same time; such uses define their function. Cities are defined by the areas inside the urban space, such as downtown, residential neighborhoods of marginalized social classes, popular districts, periphery - that is, a set of distinct areas in terms of form and social content.

The urban space also assumes a symbolic dimension in which several relations are reproduced in daily life, feelings of belonging to a place where individuals coexist, as well as social practices, beliefs, and values created over the consolidation of societies.

According to Serpa (2008, p.305), the space is what modifies the connections among spaces and facilitates flows. The integration allowed by globalization establishes that the participation in an integral spatiality, both of places and of flow, depends on the place's accessibility and on people in the technical-scientific-informational environment.

The levels of accessibility define the relations among urban space and other localities. The development of a place is related to several present infrastructure, as well as to economic activities established in the built space.

Understanding the space involves several meanings, receives different elements in a way that any and every definition is not a permanent conception; it is flexible and allows changes. The space has elements defined from their function in the maintenance of socio-spatial dynamics. Among them the infrastructures, which can be explained by the human work materialized and spatialized in the shape of buildings, automobiles, energy, plantations, and others.

Santos (2001, p. 60) believes that "the space denotes the result of constant interactions between 'fixed' and 'mobile", namely, between materiality and immateriality. The fixed can be understood as elements built by human actions and equipped with intentionality; therefore, they have functions (means of transport, energy, capital, information, communication, knowledge).

Thus, each fixed spatial element is interconnected to a succession of interactions and local and distant interdependencies, with economic, historic, social, and cultural relevance. The fixed can be denominated territorial fixed, since they are built in space, have address, and have localization - they can be georeferenced.

On the other hand, the mobiles give meaning to life and economic activities over the historical processes and are considered the direct and indirect result of actions and cross or settle themselves in the fixed, modifying their meaning and value and, at the same time, modifying themselves (SANTOS, p. 15,1988).

The concepts presented here will be necessary for better understanding the cities, considering their relations and their multi themes and scales, namely, cities, and their sets and components must be considered as systems with energy interaction vectors of different sizes and meanings. 


\subsection{Systems}

Socio-ecological

Adguer (2006) says that the concept of a SocioEcological System reflects the idea that human actions and social structures are integrated to nature and there is no distinction between social and natural systems.

\section{Complex}

The Complexity Sciences appropriated characteristics of natural systems aiming at representing the artificial ones, as close to reality as possible.

\section{GENERAL CONCEPTS RELATED TO ENERGY SCIENCES}

The basic, general concepts neces sary to understand this research refer to the energy sciences theme and shall substantiate the discussions presented here.

The energy relations of an area, usually a State, are presented in the energy balance. The energy balance refers to the study of the current landscape and the projections of energy inputs, production, consumption, and outputs in a defined spatial unit.

The energy balance's general structure is composed by primary energy, transformation, secondary energy, and final consumption.

Energetic compounds derived directly from nature, such as oil, natural gas, mineral coal, firewood, sugarcane products, plant and animal residues, uranium, hydraulic energy, solar energy, and wind energy form the primary energy. Primary sources are classified as renewable and non-renewable sources.

Secondary energy refers to energetic products resulting from the transformations centers, which forward such energy to several consumption sectors or to another transformation center. As examples, one can mention diesel oil, liquefied petroleum gas (LPG), naphtha, kerosene, and other residues derived from petroleum.

In order to the generated and transformed energy reach the consumer, it must go through the transmission and distribution system.

The distribution scenery in Brazil presents 63 energy providers plus authorized companies. In the state of São Paulo, there are 7 to 8 distributors and, in the capital, Eletropaulo provides the energy.

\subsection{Energy supply and final consumption}

Energy supply is the amount of energy made available to be consumed (final consumption). The amount of energy available to be consumed in a determined spatial unit or consumer group is defined as energy supplied.

According to BEN (2016), in 2013, the final consumption of electricity corresponded to $18 \%$ in the whole world, behind only of oil consumption, with $39.9 \%$.

According to data obtained by BEN (2016), production of energy in the state of São Paulo decreased $4.2 \%$ in 2015 when compared to the previous year. In 2014, energy production was 65.409 GWh and, in 2015, it was 62.654 GWh (BEN, 2016, p. 150).

\subsection{Energy sources}

The main energy sources presented in the energy balances and existing in the country are oil, natural gas, electric energy, mineral coal, wind energy, biodiesel, and sugarcane products.

Brazil's electric matrix is composed by the following primary sources: wind, solar, hydroelectric, nuclear, thermal, sugarcane bagasse, and firewood sources.

Brazil has an original electric matrix that is predominantly renewable, specially the hydraulic generation, which corresponds to $64 \%$ of the internal supply. Renewable sources represent $75 \%$ of the internal energy supply in Brazil (BEN, 2016, p. 17).

\subsection{Consumer economic sectors}

The final consumption of energy encompasses all sectors of economic activity, which converge primary and secondary energies. Final consumption is the sum of energy and non-energy consumptions. Energy consumption is represented by sectors such as residential, commercial, public buildings, agribusiness, transport sector, industrial, and non-identified consumption.

The final consumption of energy is presented in national and state energy balances by the following sectors: energy, residential commercial, public, agribusiness, transportation, and industrial.

Among all sectors, the residential sector, when added to others (except industry and transportation), represents over $50 \%$ of global energy consumption. In 2013, of 1677106 tep, 56.2\% derived from sectors other than the industrial and the transportation sectors (BEN, 2016).

The residential sector is supplied, predominantly, by electricity, with almost $46 \%$ of participation; in 2015 , it corresponded to almost 11.300 tep (BEN, 2016). Both firewood and petroleum liquefied gas (PLG) are still significant sources in the sector and together they represent over $50 \%$ of the total of the sector's participation, while natural gas represents little over $1 \%$.

The chart presented by BEN (2016), concerning the final consumption of the residential sector during the analyzed period shows that energy consumption grows to the detriment of firewood. This behavior certainly corresponds to the correlation between economic development and consumption by energy sources in the residential sector. That is to say that as a region develops, its final consumption enhances, tending firstly to be of energy consumption. 


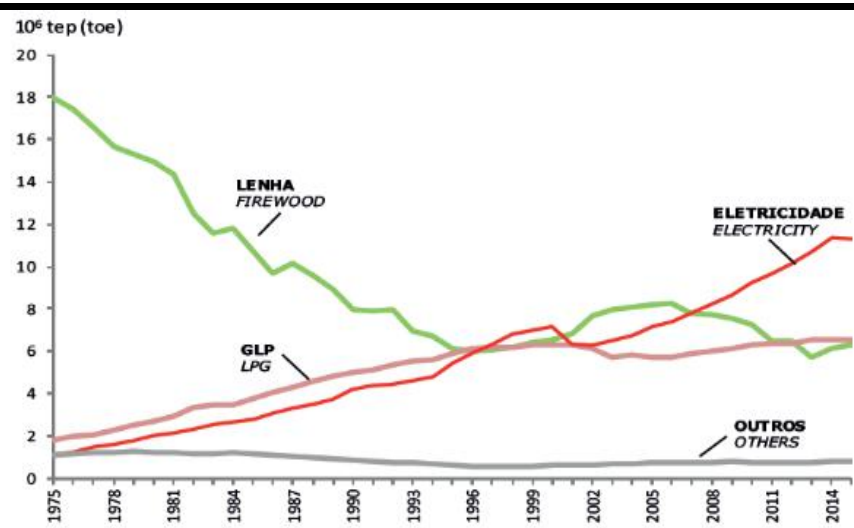

Fig.1: Final consumption of energy in the residential sector(1975-2014)

Source: BEN, 2016.

In 2015, the residential sector presented the second largest electricity consumption of the country, representing a little more than $21 \%$ of participation, with $131 \mathrm{TWh}$ in the year (BEM, 2016, p.40).

In 2015, the state of São Paulo registered the highest energy consumption in residencies compared to other states, corresponding to 38.212 GWh (BEN, 2016). Thus, it can be observed the state's expressiveness in residential consumption in comparison to the rest of the country.

\section{APPLIED CONCEPTS}

The concepts applied to this topic concern the theme of this research and are presented in the following structure: Urban Energy Systems, Energy Safety, Threat, Risk, Fragility, Resilience, Adaptability, Transformability, and Vulnerability.

\subsection{Urban Energy Systems - UES}

Urban Energy Systems (UES) can be defined based on the concept of Socio-Ecological System (SES), which is characterized as a system that includes the social (human) and biophysical subsystems in mutual interaction (GALLOPÍN et al., 1991). The SES, as well as the UES, can be applied in different scales, from local communities and their environment to global systems formed by all human communities and the biosphere (GALLOPÍN, 2006).

Based on the concept of socio-ecological systems, one can consider the energy context interconnected (mainly the question of electricity and transportation) and it is formed by social and biophysical subsystems. The UES refers to a complex system that is influenced by environmental, ecological, social, and market factors.

According to Gruble et al. (2012), the term "Urban Systems" is used for the urban phenomenon of a functional perspective, as well as a traditional territorial or administrative perspective. Thus, according to the author, urban energy systems encompass all components related to consumption and provision of energy services associated to functional urban systems, regardless of location, uses, and energy conversions.

Considering the natural tendency of economically developing countries to reach urbanization and consumption levels of developed countries, global challenges concerning access to clean energy and energy safety services have to take into account the limitations and opportunities of urban energy systems in local scale.

According to Walker et al. (2004), the dynamic stability of human and natural systems emerges from the complementarity and understanding of the following features: resilience, adaptability, and transformability. Adaptability can be understood as the capacity of managing the system's resilience, and it may employ managing tools in order to minimize the vulnerability of urban energy systems.

\subsection{Energy Safety}

According to Winzer (2011), reaching energy safety is among every nation's most important goals. In order to reach such goal without conflicts among countries (keeping in mind that energy systems do not follow political frontiers), the term energy safety must be well defined and clearly measured.

During the revision of the literature on the theme, it is possible to observe that there is no consensus, neither on the academics, nor on the legislators' part when it comes to defining "energy safety" [see in Sovacool(2011), the 45 definitions employed for the term]. However, the present research presents some definitions that were considered important, as seen in the consulted literature.

The international Energy Association (IEA, 2016), for example, defines energy safety as the continuous availability of energy sources for a fair price, so to balance economic development and environmental aspects. In this definition, it is clear the understanding that energy safety 
is similar to energy supply safety, which is common among other authors (e.g. Löschel et al., 2008; Kruyt et al., 2009;

Australian Government, 2011; Winzer, 2011).

Parag (2014) criticizes the interpretation adopted by several academics and governments because it does not take into consideration, among other things, the active role that final consumers have over urban energy systems, above all in times of discussions about low-carbon economies. According to the author, energy safety must be approached as energy services safety in order to incorporate the complex nature of urban energy systems: the interaction among energy infrastructures, final uses, and behavioral, social, and cultural aspects of energy use.

When incorporating such aspects in what concems energy, Jansen (2009) defines energy services safety as "the measure in which population in a certain area (country or region) can have access to energy services of adequate quality for a fair and competitive price".

At the same time, the IEA defines energy safety considering the equilibrium of economic development and environmental aspects for a fair price. Jansen (2009) focuses on the population with access to energy services with quality and fair price, but does not mention environmental aspects.

It is perceivable that all definitions are concerned with the challenge of offering energy services with quality and fair prices, even if not all authors consider environmental questions. Thus, the focus is shifted to consumers who desire quality services that meet their current and future demands. This is an intrinsic need of consumer goods orienting the identification of direct and indirect variables.

\subsection{Threat and risk}

The Chertoff Group (2014) defines threat as the potential capacity or pretension to cause damages and it is related to a probability (or potentiality) of certain damage occurring, being a non-null variable. However, Turner et al. (2003) argue that threats are dangers to a system that include disturbance, stresses, and stressors (source of stress).

In addition, Sovacool (2001) understands that threats can be defined from the system's scales, dividing them into three categories: macro, micro, and meso (middle or intermediate). Macro threats are those that impinge on the global system; micro threats impinge on local scale; and meso threats are located between the global and local scales.

Urban energy systems are limited by economic, technical, social, political, and environmental questions, which can represent threats. In the point of view of energy safety, it is understood that these threats are caused by the existence of a factor over the energy supply chain.
The idea, common to all these definitions of energy safety, can be described as "the absence of protection or adaptability to threats caused by an impact on the energy supply chain".

The concept of risk can be defined as the possibility that consequences from any event or action damage aspects valued by humans (Kates \& Kasperson, 1983; Hohenemser, Kates, \& Slovic, 1983). For example, the falling of branches on energy distribution cables causing power failure. The Chertoff Group (2014) presents risk as the intersection of three aspects: threat, vulnerability, and consequences.

\subsection{Fragility}

Fragility can be defined as propensity to deterioration or rupture of a system, being opposed, then, to system resistance and tenacity. This term is present in socio-ecological systems, economic sciences, urban systems, resistance of materials, and others.

Fragility is categorized by the consequences that the deterioration or rupture can cause upon certain impact. Fragility is evaluated in the face of a threat or risk. It is only active if said impact promotes alteration, deterioration, or rupture to a system.

Klemkosky (2013) defined the economic systems as fragile. Such fragility can cause economic impacts, as in Japan and in the United States, and usually generate periods of low economic growth.

On the other hand, Commins (2011), who studies the fragility of the African urban system, states that fragility manifests itself in a context of crisis of governmental deterioration and prolonged political conflicts in the urban scope. Fragile governments lose their capacity of providing basic and safety services to their citizens.

In urban areas, fragility is intensified by urban energy systems that are mostly fed - or, in most cases, exclusively fed - by the National Interconnected System (SIN) and by local distributors. The UES' fragility is also intensified because it refers to a systemstrongly dependent on a single source, electric power, with emphasis on demands and spaces, such as building set with data servers, elevators, and air-cooling central systems. Such spaces become more fragile the less diversified the energy sources that supply them.

In the case of a building set, the fragility of the system can be managed with complimentary sources or energy efficiency, as with cogeneration, i.e., diversification measures that decrease the dependence on SIN and that can minimize the building system's fragility.

\subsection{Resilience}

According to Folke et al. (2010), the resilience 
concept was originally introduced in socio-ecological systems by Holling (1973) as a concept for understanding the capacity that ecosystems have of persisting in their original state even when subject to disturbances.

Yet Walker et al. (2004) defines resilience as the capacity that a system has of absorbing disturbances and reorganizing itself while retaining the same function, structure, and identity. In this sense, one can point out some policies implemented in the city of São Paulo to decrease traffic and that, at time, culminated in unexpected behaviors. The first example was the creation of bus corridors, which could encourage people to use public transport instead of private, with the added bonus of spending less time in traffic.

This measure can promote the change towards the use of public transport in detriment of private transport or it can have no effect in the behavior of users. The choice of continuing to use private cars can increase travel time when the same route can be travelled in public transport. In this case, one can see resilience in the user who, instead of time, is prioritizing comfort and adapting to his new and longer stay in traffic during his dislocations - here, the user experiences the so-called "adaptability". However, if the user chooses the public transport, he can spend less time travelling, but naturally relinquishes certain comfort - this change of habits represents transformability.

An application of such concepts of socioecological systems can be seen in the concepts of mechanics of materials presented in Figure 2. A material subjected to axial loading will suffer deformations. If these deformations do not surpass the limit called "elastic region", the deformations will not be permanent and the material will come back to its original state. If the deformations go beyond the elastic region and reach the plastic region, then they will become permanent.

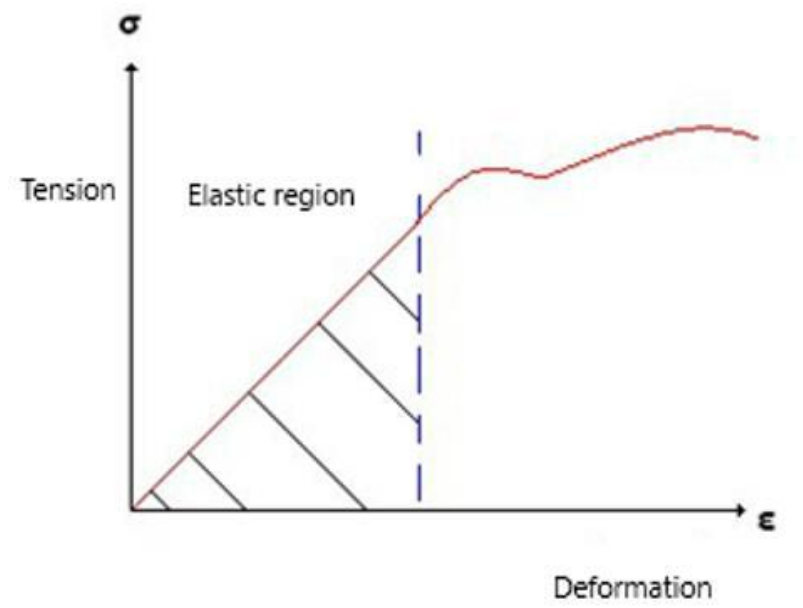

Fig.2: Elastic region of deformations on a material

In this context, resilience can be defined as the material's elastic region, in which deformations are dis solved and it will return to its initial state. The maximu $\mathrm{m}$ energy necessary to the material overcomes the elastic region and reach the plastic region can be defined as resistance. The precariousness refers to the current deformation of the system in relation to the maximu $\mathrm{m}$ deformation of the elastic area and it is, then, a function of time. Lastly, panarchy happens when the characteristics described in this system are altered by sudden and unexpected changes in variables external to the system.

\subsection{Adaptability and Transformability}

Adaptability has been discussed in several scientific areas, for example, in the energy systems. Authors Grubb e Minh Ha Duong (1995) say that energy systems and technologies adapt themselves to external pressures.

Walker et al. (2004) defines adaptability in the context of socio-ecological systems, such as the capacity that human agents have of influencing a system's resilience, changing its latitude, resistance, or precariousness. Going to back to the example of the bus corridors, their creation can be considered a measured that influenced resilience, increasing the system's latitude, resistance, and preciousness.

When going through a process of adaptability, a systemcan have its resilience limit pulled closer or pushed far away from its current state (alteration in its latitude). It can have an increase in its difficulty of reaching latitude (alterations in its resilience) or even have its current state moved, i.e., not in the latitude direction (alterations in the precariousness level).

Carpenten e Brock (2008) distinguish the term adaptability from transformability and state that, even though changes occur in the internal demands and forces external to the system, it can adapt to maintain certain processes and not transform itself into a fundamentally new system.

Transformability occurs when a current system is 
unsustainable, when the resilience zone has been surpassed, and a fundamentally new system is formed. Folke et al. (2010) considers the concept a capacity of crossing limits reaching new paths of development.

Based on these definitions, it is possible to believe that the city of São Paulo and its metropolitan region may be facing this moment of energy transformability concerning transportations. And it can also be experiencing the so-called adaptability concerning its demand for electricity.

\subsection{Vulnerability}

According to Calvo e Dercon (2005), the term vulnerability comes from the Latin "Vulverare", which expresses the idea of being hurt and suffering damages, associated to dangers and threats and not to general uncertainties.

Gallopín (2006) evaluated that this term is usually understood as the susceptibility of a system to a potential damage or transformation when subjected to disturbances or environmental pressure, instead of a real damage measure. When we compare that to the urban vulnerability, it comes from the fragmentation and segregation of the urban space.

The concept of vulnerability is not a consensus among the studies on the theme and it varies in several areas of study. A revision of the definitions of the concept of vulnerability can be found in Figueiredo et al. (2010).

The system's vulnerability, as defined by Doorman et al. (2006), is the system's insufficient capacity of bearing an unwanted situation. The unwanted situation is considered any unexpected externality that may disorganize the current shape and is, then, understood as a threat or risk.

\section{URBAN ENERGY VULNERABILITY: CONNECTING THE CONCEPT}

Energy systems' failures can affect the final user more or less and this intensity is called vulnerability. The availability of energy is connected to the wellbeing and safety of the population, from simpler cases as a consumer's food stock, the trajectory of an elevator in a building, the thermal comfort created by air conditioning, to the more complex case of the operation of a hospital.

The implantation of a network that favors the distributed generation, with micro generators in urban centers, can contribute to the reduction of the UES' vulnerability, since the exposition of a generation center to a threat does not compromise the operation of other centers. In this context, a mathematical formula is proposed in order to evaluate the vulnerability according to the probability of failure of the electric system, taking into consideration the population the can be eventually affected.

$$
\mathrm{V}=\mathrm{q} \cdot \sum \mathrm{P}
$$

In which:

$V$-Vulnerability;

$q$-Probability of failure of electric system (FEC, DEC);

$P$-Population of evaluated area.

It is understood that vulnerability is a function between threat and damage intensity, thus being a portion of the relation of fragility, not considering consequence.

$$
\mathrm{V}=\mathrm{f}[\mathrm{A}, \mathrm{ID}]
$$

In which:

V_Vulnerability;

A -Threat;

ID - Damage intensity. Refers to portion of the fragility relation.

The threat represents the risk of a certain part of the population being without electric power or public transportation, for example. The treat can be defined as part of the study of FEC and DEC (frequency and length of systemfailures), which can express a threat when its linear and non-linear projection is made.

The threat considers the rupture or deformation per se and the probability of its occurrence, that is, the threat is the variation on axis $\mathrm{X}$, referring to the sceneries 1 and 2.

$$
\mathrm{A}=[\Delta \mathrm{x}, \mathrm{P}]
$$

In which:
A -Threat;
-Variation on axis $\mathrm{X}$;
$\mathrm{P}-$ Probability of occurrence of threat. 


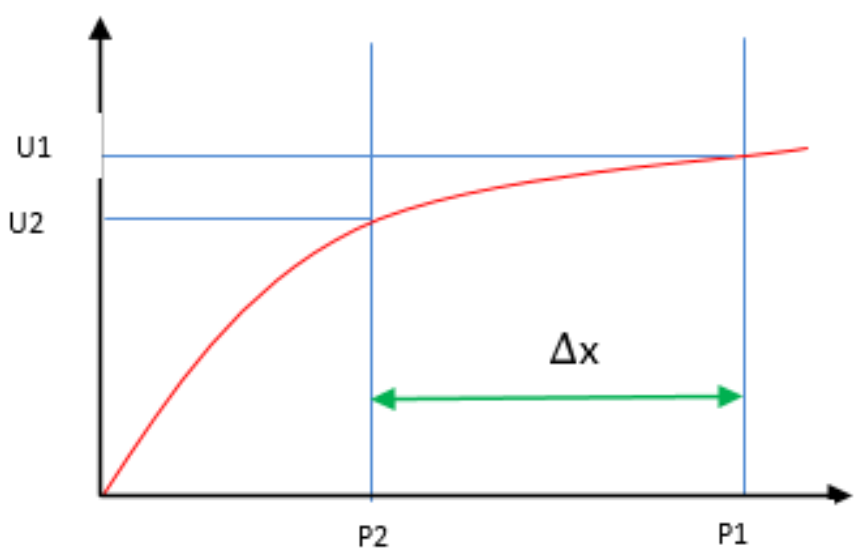

Fig.3: Utility's resilient region. The intensity of damage can be measured
through the hours of congestion caused by it, for $U^{\prime}=\frac{d U}{d x}$ example. All examples are vulnerability measures expressed by utility, rather, the marginal utility strongly discussed and applied in economic theory.

The concept of disutility encourages the $=\left[\mathrm{U}, \mathrm{U}^{\prime}\right]$

The marginal utility, here expressed by U', represents one of the manners of measuring the satisfaction, or the consumption vector of goods and services, represented from the measure of how much satisfaction increased as one unit of $\mathrm{X}$ increases.

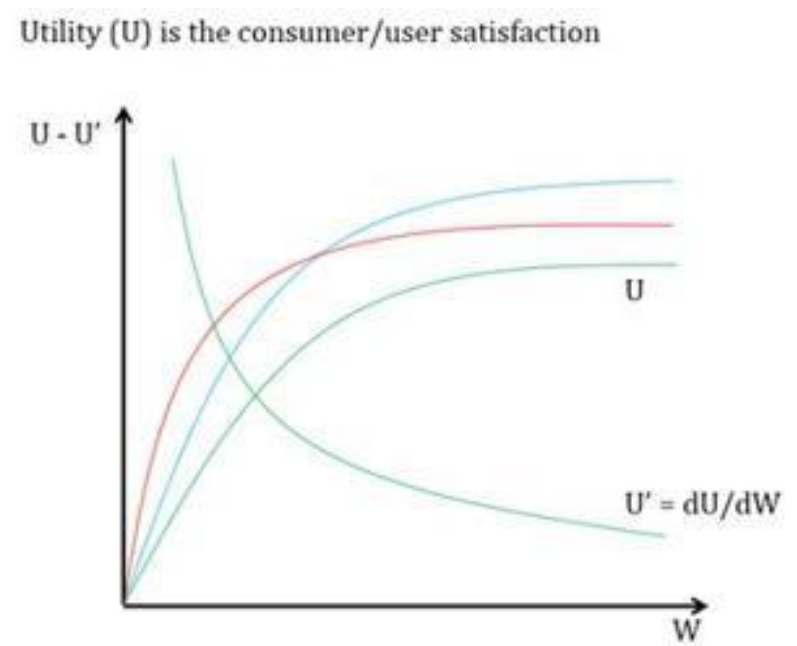

Fig.4: User's marginal utility curve (U).

What is proposed here is the use of the concept of urban vulnerability to evaluate the neighborhood effect in a city, which is defined as the sum of each scenery' utility and its respective probability of happening.

This concept is proposed as a means of measuring the vulnerability because it allows evaluating in an integrated manner each region's individual vulnerability, taking into account the integration of such regions and the influence of energy flows in the system's behavior as a whole.

The utility curve is determined in function of the energy flows among regions and determines the way in which other regions are capable of servicing the population of regions where failures occur. 
The importance of this concept is paramount for evaluating the present scenery and how the technological changes in the energy model can influence the utility curve positively.

\section{FINAL CONSIDERATIONS}

Due to the strong energy dependency of the great urban centers, it is necessary to create managing tools and to implement new, integrative technological innovations using several energy vectors, aiming at efficiency and system safety.

Thus, a reductionist approach focused on isolated elements would not be enough to understand the processes in an urban energy system. Then, this conceptual discussion, based on the theoretical and philosophical development of socio-ecological systems, has the main goal of promoting the urban energy planning and proposing public policies to decrease urban energy vulnerability.

In this regard, based on the concepts discussed here, mainly that of the Urban Energy Vulnerability and the territorial space's importance and complexity, the city of São Paulo is seen as an ideal area for a case study in future studies. Therefore, it must be analyzed in detail in what concerns its formation and energy-space-time relations, presenting its background and relations with the energy and electric demands.

\section{ACKNOWLEDGEMENT}

The authors gratefully acknowledge support from Shell and FAPESP through the "Reserch Centre for Gas Innovation - RCGl" (Fapesp Proc. 2014/50279-4), hosted by the University of Sao Paulo, and the strategic importance of the support given by ANP (National Oil, Natural Gas and Biofuels Agency) through the R\&D levy regulation, as well as the University of São Paulo, and CAPES (Proc. 23038.003802/2014-53).

\section{REFERENCES}

[1] AMARO, J. J. V. Sociedades complexas e risco ecológico - Epistemologia e meio ambiente na atual teoria de sistemas. Núcleo de Pesquisa e estudos em educação ambiental e transdisciplinaridade, Universidade Federal de Goiás (UFG). Vol. 3, p. 4759, 2013.

[2] ARIAS, D. V. Gestión de riesgosenel Sector energético.Apresentação do curso Capev Capacitación Energética Virtual. Organização Latino-Americana de Energia (Olade), 2012.

[3] ARNOLD, M.; BARTH, V. Open Inovation in Urban Energy Systems.Energy Efficiency, 5:351-364, 2012.

[4] CALVO, C.; DERCON, S. Measuring individual vulnerability. Department of economics. Discussion paper series. University of Oxford, Number 229, 2005.

[5] CARPENTER, S. R.; W.A. BROCK. Adaptive capacity and traps. Ecology and Society 13 (2):40, 2008. Available at: $<\mathrm{http}: / /$ www.ecologyandsociety.org/vol13/>. Access on: 04/nov/2013.

[6] COMMINS, S. Urban Fragility and Security in Africa. Africa Security Brief, $N^{\circ} 12$. Africa Center for Strategic Studies. <http://africacenter.org/wpcontent/uploads/2011/04/ASB-12_FinalforWeb.pdf>. Access on: 27/nov/2013.

[7] FIGUEIREDO, M. C. B. Análise da Vulnerabilidade Ambiental, 2010. Embrapa - Empresa Brasileira de Pesquisa Agropecuária. Ministério da Agricultura, Pecuária e Abastecimento. Available at: <http://www.cnpat.embrapa.br/cnpat/cd/jss/acervo/D c_127.pdf>. Access on: 27/nov/2013.

[8] FOLKE, C. ET AL. Resilience Thinking: Integrating Resilience, Adaptability and Transformability. Ecology and Society 15(4): 20. 2010. Available at: <https://www.ivey.uwo.ca:444/cms media/222506/R esilience_thinking_IntegratingResilience__Adaptabi lity_and_Transformability.pdf/>. Access on: 04/nov/2013.

[9] GALLOPÍN, G. C. Las dimension es humanas del cambio mundial: vinculación de losprocesosmundiales y locales. Revista Internacional de Ciencias Sociales. pp. 130, 707-718, 1991.

[10] GALLOPÍN, G. C. Linkages between vulnerability, resilience, and adaptive capacity. Global Environmental Change, 16, pp. 293-303, 2006.

[11] GRUBB, M. E MINH HA DUONG, T. C. The economics of changing course: Implications of adaptability and inertia for optimal climate policy. Energy Policy. V. 23, pp. 417-431, 1995.

[12] HIDALDO, B.D.; As divisões territoriais do município de São Paulo: uma proposta de classificação por meio da análise dos Distritos. Monograph. São Paulo, p. 116, 2013.

[13] JANSEN, J.C. Energy Services security: concepts and metrics, expert paper submitted as input to the ongoing IAEA project: Selecting and Defining Integrated Indicators for Nuclear Energy, Energy Research Centre of the Netherlands, 2009. Available at

http://www.ecn.nl/docs/library/report/2009/e09080.p df. Access on: 25/mai/2016.

[14] HOHENEMSER, C., KATES, R. W., \& SLOVIC. The nature of technological hazard. Science, pp. 220, 378-384, 1983 
[15] KATES, R. W., \& KASPERSON, J. X. Comparative risk analysis of technological hazards. A review. Proceedings of the National Academy of Sciences, pp. 80, 7027, 1983.

[16] KLEMKOSKY, R. Financial system fragility . Business Horizons. Vol. 56, pp. 675-683, 2013.

[17] Institute for Energy and Transport. European Comission. Available at:

[18] <http://ses.jrc.ec.europa.eu/complex-systemscience-smart-grids >. Access on: 27/nov/2013.

[19] KRUYT, B., D. VAN VUUREN, H. DE VRIES \& H. GROENENBERG. Indicators for energy security, Energy Policy 37(6), pp. 2166-2181, 2009.

[20] LEFEBVRE, HENRI. 2001. O direito à Cidade. Tradução Rubens Eduardo Frias. São Paulo, Centauro, 2001.

[21] PIMENTEL, D. et al. Economic and environmental threats of alien plant, animal, and microbe invasions. Agriculture, Ecosystems \& Environment. Vol. 84, p. 1-20, 2001.

[22] RUTTER, P.; KEIRSTEAD, J. A brief history and the possible future of urban energy systems. Energy Policy, pp. 50, 72-80, 2012.

[23] SANTOS, M. A Natureza do Espaço. Técnica e Tempo. Razão e Emoção. $2^{\text {nd }}$ ed. São Paulo, Hucitec, 1997.

[24] SERPA, A., org. Apresentação. In: Espaços culturais: vivências, imaginações e apresentações [online]. Salvador: EDUFBA, 2008. pp. 9-11. ISBN 978-85232-1189-9. Available from Scielo Books O direito à Cidade. Transl. Rubens Eduardo Frias. São Paulo, Centauro, 2001.

[25] SOVACOOL, B.K. (ed). The Routledge Handbook of Energy Security (New York: Taylor \& Francis), 2011.

[26] TURNER II., B.L., KASPERSON, R.E., MATSON, P.A., MCCARTHY, J.J., CORELL, R.W., CHRISTENSEN, L., ECKLEY, N., KASPERSON, J.X., LUERS, A., MARTELLO, M.L., POLSKY, C., PULSIPHER, A., SCHILLER, A. A framework for vulnerability analysis in sustainability science. Proceedings of the National Academy of Sciences of the United States of America 100 (14), pp. 8074 8079, 2003.

[27] WALKER, B., H., ET AL. Resilience, adaptability and transformability in social-ecological systems. Ecology and Society 9 (2):5, 2004. Available at: <http://www.ecologyandsociety.org/vo19/iss 2/art5>. Access on: 04/nov/2013. 